Supplement of Geosci. Model Dev., 14, 4891-4908, 2021

https://doi.org/10.5194/gmd-14-4891-2021-supplement

(C) Author(s) 2021. CC BY 4.0 License.

(c) (i)

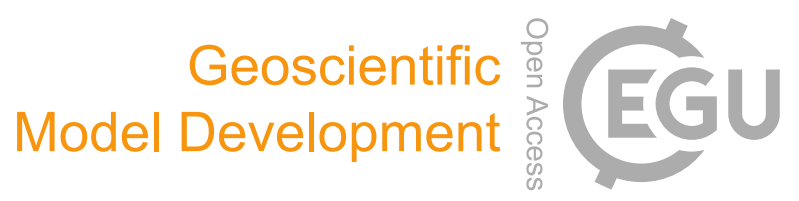

Supplement of

\title{
Sensitivity of Northern Hemisphere climate to ice-ocean interface heat flux parameterizations
}

Xiaoxu Shi et al.

Correspondence to: Xiaoxu Shi (xshi@awi.de)

The copyright of individual parts of the supplement might differ from the article licence. 
(a)

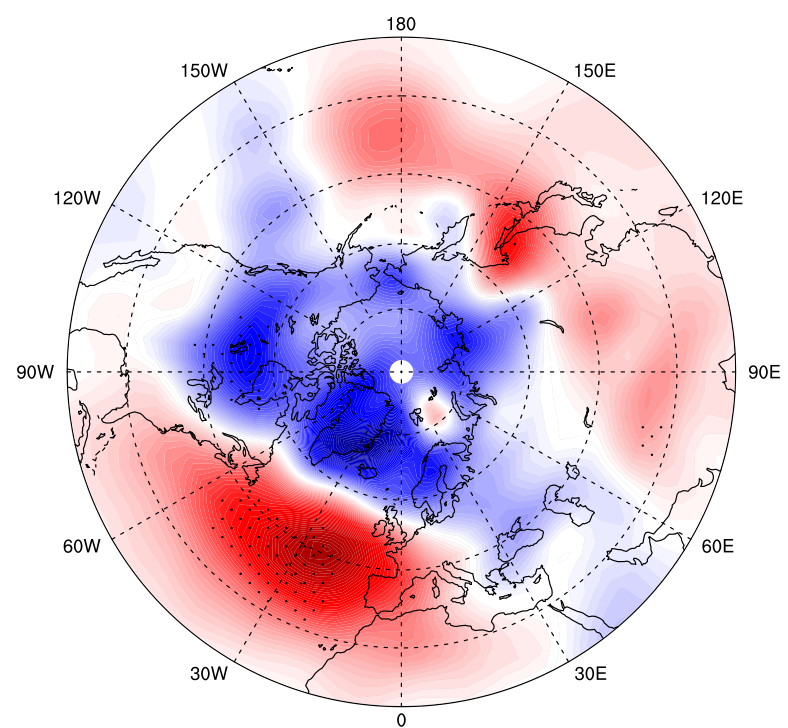

(b)
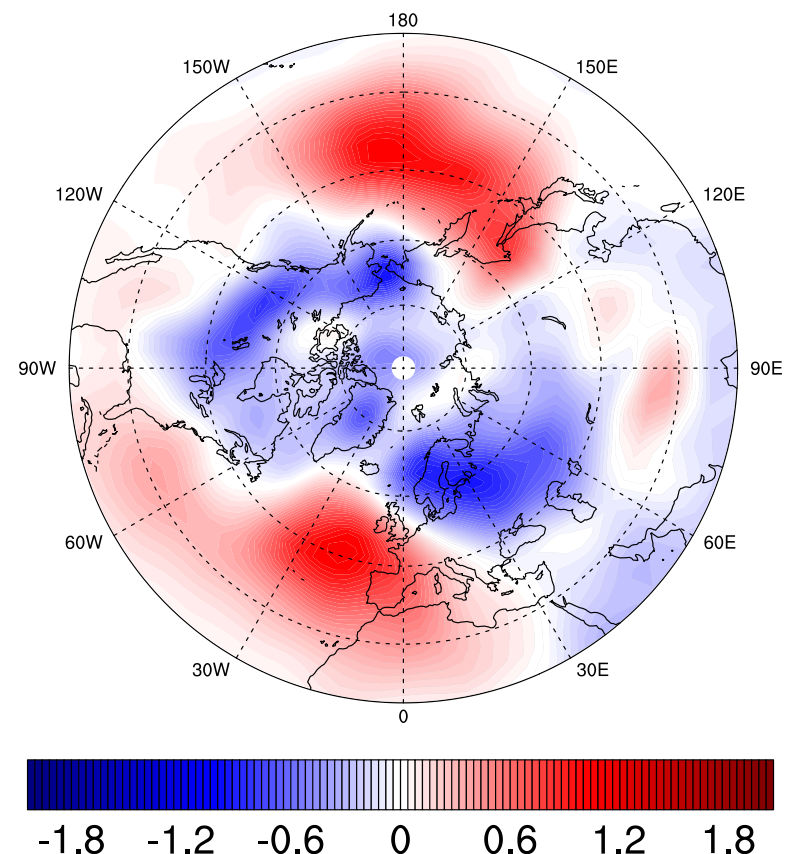

Figure S1. Anomalies in boreal winter sea level pressure (a) COSMOS-3eq35 - COSMOS-icebath, and (b) COSMOS-3eq35 - COSMOS2eq for the time window of 800-900th model year. Units: hPa. 
(a)

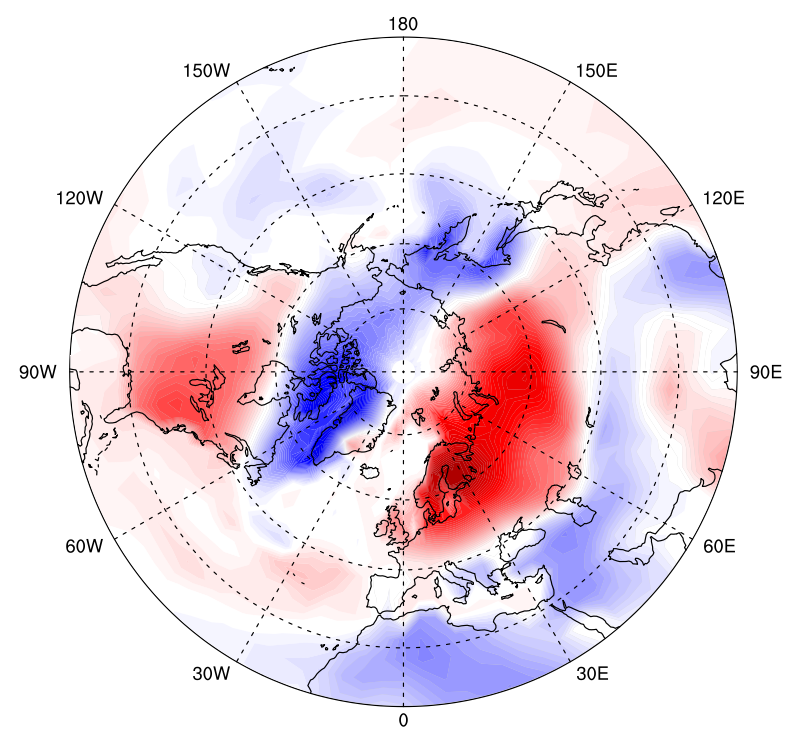

(b)
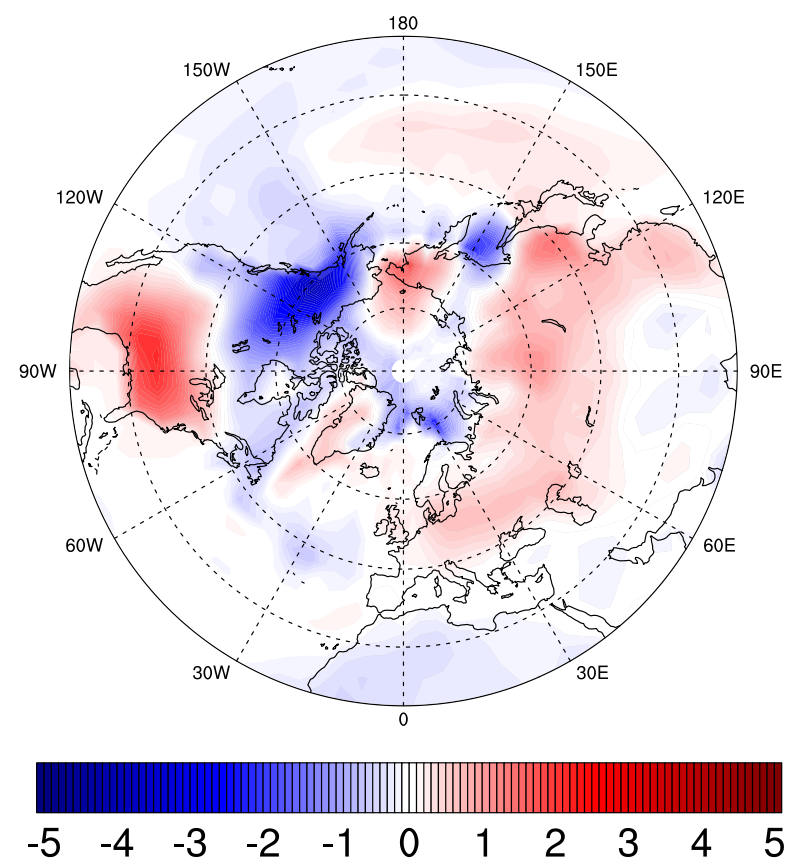

Figure S2. (a) Composite map of surface air temperature and NAO index for COSMOS-3eq35. It is calculated by averaging surface air temperature anomalies (departure from the annual mean state) during years when the NAO index exceeds one standard deviation. (b) Same in (a), but for the the North Pacific (NP) index. Units are K. 


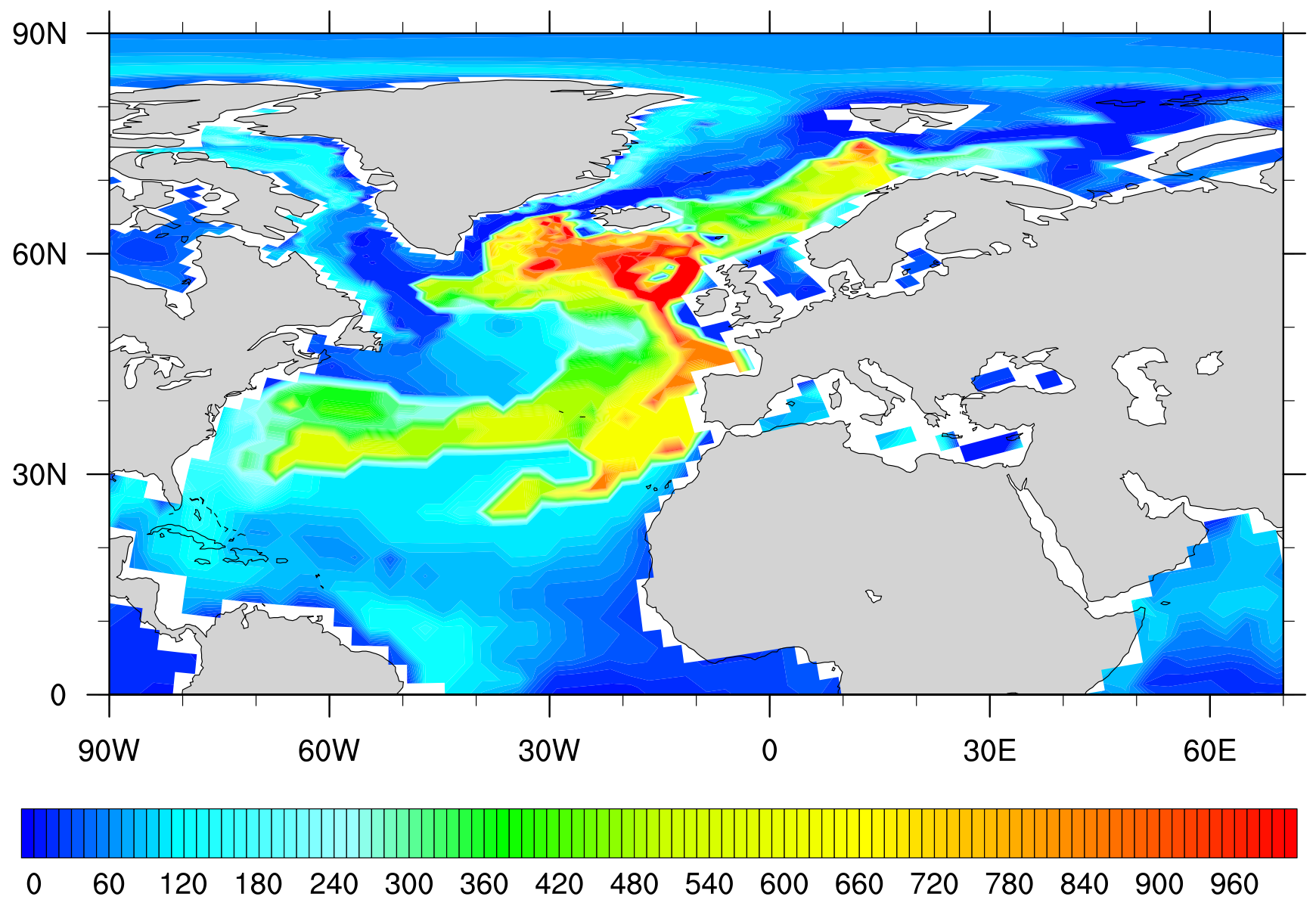

Figure S3. Distribution of North Atlantic mixed layer depth in MPIOM-3eq35. Units are m. 